Encontro Nacional de

Economia Industrial e Inovação
Indústria e Desenvolvimento Econômico:

desafios e perspectivas

18 a 20 de setembro de 2018

Uberlândia - Minas Gerais

\title{
A Elasticidade Preço nas Equações de Demanda por Importações Considerando a Qualidade dos Produtos: Estimativas para a Economia Brasileira (1996-2013).
}

\author{
Ariane Danielle Baraúna da Silva \\ Álvaro Barrantes Hidalgo ${ }^{2}$
}

\begin{abstract}
RESUMO:
A competitividade no comércio internacional tem se baseado cada vez mais na qualidade dos bens negociados, o que torna a qualidade uma variável chave na determinação dos ganhos de comércio. Estudos empíricos recentes argumentam que os modelos tradicionais de comércio,que ignoram o papel da qualidade dos produtos, geralmente obtêm elasticidades preço viesadas, comprometendo a avaliação correta dos determinantes do comércio, bem como a formulação de políticas comercias. $O$ presente artigo tenta quantificar o efeito da qualidade sobre os fluxos de importação do Brasil, para isso, são estimadas equações de demandapor importação, incluindo umaproxypara a qualidade dos bens importados, baseado em dados agrupados em painel considerando os vinteprincipais parceiros comerciais do Brasil. Os resultados mostraram que a demanda por importações brasileiras é mais influenciada pelos preços do que pela qualidade, ao contrário dos resultados obtidos pela literatura aplicada aos países desenvolvidos. Ao considerar o papel da qualidade como um dos determinantes da demanda por importações relativas, foi verificado que seu impacto sobre as importações de bens manufaturados é positivo e significante, já para o conjunto de produtos básicos a variável apresentou coeficiente negativo e insignificante na maior parte das estimações. A introdução da proxy para a qualidade aumentou o coeficiente do preço, isso ocorreu de forma mais expressiva nas estimações para o segmento de manufaturados, apoiando a hipótese de existência de viés das elasticidades quando estimadas sem considerar a diferenciação de produtos.

Palavras-Chave: Elasticidade das Importações, Qualidade, Competitividade, Diferenciação.
\end{abstract}

\begin{abstract}
:
The competitiveness in international trade has been based increasingly on the quality of traded goods, which makes the quality a key variable in determining the trade gains. Recent empirical studies argue that the traditional models of trade, ignoring the role of product quality, usually get elasticities biased price, compromising the correct evaluation of the determinants of trade and the development of commercial policies. This article attempts to quantify the effect of the quality of Brazil's import flows, for this, import demand equations are estimated, including a proxy for the quality of imported goods, based on pooled data panel considering the twenty major trading partners of Brazil. The results showed that the demand for Brazilian imports is more influenced by price than by quality, unlike the results obtained in the literature applied to developed countries. When considering the role of quality as one of the determinants of demand for imports on, it was found that its impact on imports of manufactured goods is positive and significant, since for all commodity variable showed a negative and insignificant coefficient in most estimations. The introduction of proxy for quality increased the price of the coefficient, this occurred more significantly in the estimates for the manufacturing sector, supporting the hypothesis of elasticities bias existence when estimated without considering the product differentiation.
\end{abstract}

Keywords: Elasticity of Imports, Quality, Competitiveness and differentiation.

Código JEL:F12, F14.

\footnotetext{
${ }^{1}$ Doutora em Economia (PIMES/UFPE).

2 Professor Titular (Decon/UFPE).
} 
Área 1- Indústria e Competitividade.

\section{INTRODUÇÃO}

A qualidade dos bens produzidos por uma economia exerce papel fundamental para o desenvolvimento das relações comerciais, estudos empíricos recentes confirmam o aumento crescente do papel desempenhado pelo comércio de produtos verticalmente diferenciados. Carmo e Bittencourt (2011)verificaram que em todas as relações bilaterais do Brasil com os países da OCDE o comércio intraindustrial vertical (CIIV) é superior ao comércio intra-industrial horizontal (CIIH), onde os produtos exportados pelo Brasil possuem qualidade inferior a dos produtos importados, Ganço(2011) encontra o mesmo resultado quando considera os 10 maiores parceiros comerciais.

Apesar do papel desempenhado pela qualidade nos fluxos de comércio, a maior parte dos estudos empíricosmantém o modelo tradicional e não se baseiam na nova teoria do comércio que considera a existência de produtos diferenciados. A teoria tradicional explica o comércio com base em dotações relativas de fatores de produção ou em diferenças de produtividade na produção de bens homogêneos. A nova teoria, por outro lado, considera os modelos de diferenciação horizontal e vertical do produto como uma fonte de comércio intra-indústria. Uma literatura crescente tem argumentado que a elasticidade preço estimada com base em modelos tradicionais pode torna-se viesada comprometendo as análises baseadas em suas estimativas.

Nesse contexto, valores baixos ${ }^{3}$ para as elasticidades preço em modelos de demanda por importações são geralmente interpretados como uma consequência direta da diferenciação do produto. No entanto, estudos recentes têm mostrado que valores baixos de elasticidades preço da demanda derivadas de equações tradicionais de comércio representam um viés de subestimação, relacionada, entre outros fatores, à ausência de qualquer variável explícita para mensurar o grau de diferenciação dos bens. Em tais equações os preços relativosretratam um duplo efeito: um impacto negativo do preço relativo para uma determinada qualidade (efeito preço "puro") e um efeito positivo da qualidade. A combinação dessas duas dimensões leva a subestimação do efeito preço. Para corrigir esse viés um termo que represente a qualidade deveser adicionado,retirando dessa forma a influência desta variável nas estimativas de elasticidade preço, e só assim será possível obter o efeito preço "puro".

O objetivo deste artigo é propor o uso de medidas mais diretas paraa qualidade dosbens, introduzindo-as nas equações de demanda por importações brasileiras, seguindo a metodologia proposta por Crozet e Erkel-Rousse (2004). Com isso, será possível avaliar o impacto dessa nova variável sobre a elasticidade preço da demanda por importações. O estudo dessa questão é relevantenão apenas para o entendimento das elasticidades preços no comércio internacional e sua relação com a qualidade dos bens, mas também para a formulação deadequadas políticas de comercio exterior.

A fim de atingir os objetivos apresentados, além desta introdução, o artigo conta com mais quatro seções. A seção 2 apresenta uma revisão da literatura sobre os trabalhos relacionados ao tema; em seguida, na seção 3, detalhamos o modelo bem como os dados utilizados e a metodologia econométrica. Os resultados da estimação são apresentados e analisados na seção 4. Por fim, a seção 5 apresenta as principais conclusões do trabalho.

\section{REVISÃO DA LITERATURA}

Nesta seção do trabalho é apresentada uma breve revisão da literatura empírica nacional e internacional sobre as elasticidades em modelos de comércio internacional.

$\mathrm{Na}$ literatura nacional, predominam as estimações com dados agregados e não háconvergência entre os resultados das referidas elasticidades, apesar da relativa extensão de publicações sobre o tema.Tradicionalmente, os modelos de comércio assumiam um mercado em concorrência perfeita e bens perfeitamente substituíveis, adotando a noção de preço único global para o comércio de bens. Neste contexto, bens comercializados teriam o mesmo valor unitário, independentemente do país produtor.

\footnotetext{
${ }^{3}$ Considerando o valor absoluto.
} 
Outros modelos assumem a existência de substituição imperfeita entre os bens, mas não consideram a heterogeneidade das preferências de forma explícita.

Um Trabalho clássico de estimação das elasticidades preço e renda do comércio exterior brasileiro é o de Zini (1988), onde foi adotado o modelo de economia pequena para as importações, e para o caso das exportações, foi assumido o modelo de substitutos imperfeitos. Foram empregados índices de quantum de comércio como variável dependente e,as exportações e importações foram divididas por grupos de origem setorial. A conclusão geral do trabalho é de que as funções de exportação e importação do Brasil são moderadamente preço-elásticas e fortemente renda-elásticas.

Seguindo a mesma linha, Carvalho e De Negri (2000) estimam equações trimestrais para os quantunsde produtos agropecuários importados e exportados pelo Brasil. Os autores concluem que as importações de produtos agropecuários são altamente dependentes da taxa de câmbio real e da taxa de utilização da capacidade doméstica instalada. As exportações brasileiras desses produtos são influenciadas basicamente pelo nível de atividade mundial e, em menor grau, pela taxa real de câmbio.

Kawamotoet al. (2013), por outro lado, encontraram elasticidades renda e preço das exportações e das importações de produtos industrializados no Brasil para o período compreendido entre os anos 2003 e 2010 utilizando dados desagregados por categoria da indústria de transformação. De maneira geral, seus resultados apontam para uma resposta mais aguda a variações na renda que a variações nos preços, tanto de exportações quanto de importações.

Skiendziel (2008) estima as elasticidades de oferta e demanda das funções de importação e de exportação para o Brasil. Os resultados para o Brasil foram bem comportados, ou seja, aderentes ao disposto na teoria. No que tange às elasticidades renda, em geral, foram encontrados valores superiores à unidade para o curto e o longo prazo, com exceção da oferta estrangeira de exportações que se assumiu, por hipótese, igual à unidade.

$\mathrm{Na}$ literatura internacional, o esforço inicial de ampliação do modelo de comércio foi dado por Armington (1969), o autor supõe que os produtos são diferenciados segundo o país de origem e que, para cada setor, a demanda total interna é atendida por um bem resultante de uma agregação CES (Constant ElasticitySubstitution) entre os bens domésticos e os importados. Os bens previamente considerados homogêneos passaram a ser tratados como heterogêneos, ou seja, não há substituição perfeita entre os mesmos, uma vez que o modelo supõe que os consumidores diferenciam os bens de acordo com o país produtor. $\mathrm{O}$ grau de substituição entre as variedades nacionais e importadas de um bem, conhecido na literatura como a elasticidade Armington, passou a representar um dos principais instrumentos empíricos da literatura sobre as elasticidades do comércio internacional.

Apesar de considerar a heterogeneidade dos bens, o modelo leva em conta apenas a diferenciação horizontal e continua supondo um mercado em condições homogêneas, mantendo as hipóteses de concorrência perfeita e retornos constantes de escala. Segundo alguns autores, como Orcutt (1950), Harberger (1953), Goldstein e Khan (1985), Madsen (1999) e Deyaket al.(1997), tais equações de comércio sofrem graves dificuldades de estimação, como elasticidades preço excessivamente baixas ou instáveis, sugerindo problemas de especificação.

A primeira tentativa empírica de análise dos impactos da diferenciação vertical sobre o comércio internacional é atribuída a Aiginger (1995). Aplicando o estudo à economia alemã, o autor determina a importância da concorrência via qualidade em um ambiente competitivo. Neste caso, a demanda também depende de outras características dos bens além dos preços, como confiabilidade, design, durabilidade, flexibilidade, entre outras. Segundo o autor, esses elementos tornam-se importantes quando o comprador está disposto a gastar mais por um bem, se estas características são adicionadas. De acordo com seus resultados, a concorrência via qualidade é mais importante na determinação dos fluxos de comércio da Alemanha do que a competição baseada nos preços.

Apesar de trazer contribuições importantes, o trabalho de Aiginger (1997) continua considerando o mercado em condições homogêneas, o que compromete os resultados. Tentando corrigir esse problema, alguns trabalhos têm dado atenção especial aos efeitos da diferenciação vertical sobre os coeficientes das equações comerciais, mostrando que a não inclusão do mesmo leva a subestimação da elasticidade preço, pois parte do efeito da variável omitida será captado pelo coeficiente dos preços fazendo com que 
apresentem valores menores do que o esperado. Segundo os autores, a adição de uma variável de qualidade permitiria retirar do coeficiente dos preços o efeito indireto da qualidade do produto.

Seguindo essa linha, Erkel-Rousse e Gallo (2002) e Crozet e Erkel-Rousse (2004) utilizam um modelo de equilíbrio geral com produtos diferenciados, tornando explícita a estrutura de preferências dos consumidores em cada mercado e capturando assim alguns elementos associados à diferenciação vertical e horizontal. Para isso os autores utilizam o modelo de preferências "loveofvariety" baseado em Spence (1976) e Dixit e Stiglitz (1977). Nessa abordagem, a diferenciação de produto pode ser compreendida como a existência de consumidores diferentes, usando variedades diferentes, onde cada demandante escolhe uma determinada variedade. Os autores mostram que assim é possível corrigir o viés da elasticidade preço das importações e melhorar o ajuste estatístico do modelo.

Os resultados de Crozet e Erkel-Rousse (2004) também confirmam a existência desse viés. Usando dados para quatro países da União Europeia, os autores estimam e comparam dois modelos, um considerando a qualidade e outro excluindo a nova variável e, em seus resultados encontraram uma elasticidade preço maior para o primeiro modelo, mostrando que a inclusão da qualidade corrige o viés de subestimação da elasticidade. Segundo os autores, esses resultados sugerem que os modelos tradicionais, ignorando a dimensão da qualidade do produto, subestimam a elasticidades preço da demanda, levando a avaliações incorretas das implicações de políticas econômicas em países.

Seguindo o trabalho de Crozet e Erkel-Rousse (2004), busca-seneste artigo agregar elementos novos ao modelo de comércio exterior brasileiro, especificamente, para a demanda por importaçõesutilizando uma análise de equilíbrio geral com produtos diferenciados quetorna explícita a estrutura de preferências dos consumidores em cada mercado, para assim capturar elementos associados à diferenciação vertical e horizontal.Com isso, pretende-se mensurar as possíveis alterações nas elasticidades da demanda por importações quando se considera um modelo com bens diferenciados.

\section{MODELO EMPÍRICO, DADOS UTILIZADOS E ESTRATÉGIA DE ESTIMAÇÃO 3.1 Modelo Empírico}

O presente trabalho busca preencher a lacuna existente nas estimações de elasticidade preço da demanda por importações para a economia brasileira através da inclusão de uma variável utilizada como proxy para a qualidade dos bens importados.O objetivo é mostrar se, de fato, como aponta a literatura supracitada, é possível obter uma melhor estimativa da elasticidade preço ao considerar a qualidade do produto em questão. Com esse objetivo, uma equação de demanda de importação foi desenvolvida, seguindo o modelo proposto por Crozet e Erkel-Rousse (2004),o qual leva em conta as novas variedades de produtos e a qualidade, utilizando dados para o período 2003-2012.

A formulação de um modelo de equilíbrio geral com produtos diferenciados requer explicitar a estrutura de preferências dos consumidores nas demandas de cada mercado capturando elementos associados a essa diferenciação. Um modo de introduzir as preferências por produtos diferenciados dos agentes especificados em modelos de equilíbrio geral consiste em adotar a abordagem de "gosto pela variedade" (loveofvariety)baseada em Spence (1976), e Dixit e Stiglitz (1977). Nessa abordagem, a diferenciação de produto pode ser compreendida como a existência de consumidores diferentes, usando variedades diferentes, onde cada demandante escolhe uma determinada variedade (Lemos, 2008).

O modelo assume que existem $I \geq 2$ países envolvidos no comércio, onde $i$ representa o país exportador e $j$ se refere ao país importador, produzindo e negociandokprodutos diferenciados, cada um dos $k$ bens produzidos possui $v$ variedades. O consumidor representativo do país $j$ maximiza a função de sub-utilidadedo tipoSpence-Dixit-Stiglitz:

$$
U_{k j}=\left[\sum_{i=1}^{I} \sum_{v=1}^{n_{k i}} \alpha_{k i j} y_{v i j}{ }^{(\sigma-1) / \sigma}\right]^{\sigma /(\sigma-1)}
$$

onde $y_{v i j}$ representa a demanda total da variedade $v$ dirigida ao produtor no país $i$, e $n_{k i} \mathrm{o}$ número de variedades do bem $k$ originadas do país $i, \sigma$ é a elasticidade de substituição entre os bens domésticos e os 
importados de diferentes origens. O parâmetro de preferência $\alpha_{k i j}$ pode ser interpretado como a qualidade do produto que é importado, descrevendo a preferência do consumidor pela variedade diferenciada $v$.

Os parâmetros da estrutura de preferências são iguais para todas as variedades $v$ do produto $k$ provenientes do mesmo país $i$. Isso ocorre pelo fato dos parâmetros de preferência derivarem essencialmente de diferenças nacionais em termos de tecnologia de produção. $\mathrm{O}$ modelo também assume que as empresas de um determinado país enfrentam as mesmas condições de produção, descritas a seguir:

- Existe uma relação biunívoca entre empresas e variedades;

- As empresas não levam em consideração as decisões das outras empresas;

- O único fator de produção é o trabalho;

- A preferência por diversidade é uma característica de mercado e não individual;

- As empresas pagam os mesmos salários a todos os trabalhadores.

- As empresas apresentam retornos crescentes de escala;

- A tecnologia é a mesma para todas as variedades.

O total de produção da variedade $(v, i)$ é dividido entre os jmercados:

$$
y_{v i}=\sum_{j=1}^{l}\left(1+t_{k i j}\right) y_{v i j}
$$

A equação (2) corresponde à condição de equilíbrio, onde $y_{v i}$ representa a parcela de produção da variedade $(v, i)$ vendida no mercado $j$ que é igual a demanda no equilíbrio de mercado. A combinação de custos de transporte ${ }^{4}$ e custos de transação é vista como a destruição de uma parte $\left(t_{k i j} y_{v i j}\right)$ da produção enviada para o mercado $j$ durante o transporte do bem do país $i$ para o país $j$.

Supõe-se que as condições de produção e transporte são idênticas para cada variedade $v$, que são vendidas em quantidades iguais, $y_{v_{1} i j}=y_{v_{2} i j}=\ldots .=y_{v_{n} i j}$, e ao mesmo preço, $p_{v_{1} i j}=p_{v_{2} i j}=\ldots . .=p_{v_{n} i j}$, no mercado $j$. A partir da condição de maximização do lucro, $p_{k i j}=c m e_{k i}$, considerando um mercado em concorrência monopolística, é derivada uma expressão de equilíbrio para o preço:

$$
p_{k i j}=c_{k i}\left(1+t_{k i j}\right) \varepsilon_{k i j} /\left(\varepsilon_{k i j}-1\right)(3)
$$

Por outro lado, a função demanda do consumidor é derivada da maximização de equação (1) sujeito a restrição orçamentária do consumidor:

(4)

$$
y_{k i j}=\left(p_{k i j} / p_{k j}\right)^{-\sigma}\left[\alpha_{k i j}^{\sigma} / \sum_{i^{\prime}=1}^{I} n_{k i^{\prime}} \alpha_{k i^{\prime} j}^{\sigma}\right]\left(E_{k j} / p_{k j}\right)
$$

Onde $p_{k j}$ representa o preço médio de produto $k$ no mercado $j$, dado por:

$$
p_{k j}=\left[\sum_{i=1}^{I} n_{k i} \alpha_{k i j}^{\sigma} p_{k i j}^{1-\sigma} / \sum_{i=1}^{I} n_{k i} \alpha_{k i j}^{\sigma}\right]^{1 /(1-\sigma)}
$$

Sendo assim, quanto maior a elasticidade de substituição $\sigma$, mais sensível a demanda em relação aos preços relativos e a qualidade. Por outro lado, $c_{k i}$ denota o custo unitário de produzir a variedade $v$ do produto $k$ no país $i, E_{k j}$ a participação do país jna receita nacional alocada no consumo do produto $k \mathrm{e}$ $\varepsilon_{k i j} \equiv-\left(\partial y_{k i j} / y_{k i j}\right) /\left(\partial p_{k i j} / p_{k i j}\right)$ a elasticidade preço da demanda para a variedade $v$ no país $j$, calculada com base na função demanda (4), que resulta em:

$$
\varepsilon_{k i j}=1+(\sigma-1)\left[1-\alpha_{k i j}^{\sigma} p_{k i j}^{1-\sigma} / \sum_{i^{\prime}=1}^{I} n_{k i^{\prime}} \alpha_{k i^{\prime} j}^{\sigma} p_{k i^{\prime} j}^{1-\sigma}\right]
$$

\footnotetext{
${ }^{4}$ A interpretação dada por Samuelson (1954) ao custo de transporte é o que ele chama de "modelagem iceberg", ele supõe que quando uma empresa, localizada em determinada cidade, envia para outra uma determinada quantidade de um bem, parte será perdida no trajeto.
} 
De acordo com Dixit e Stiglitz (1977), a expressão (6) implica que $\varepsilon_{k i j}$ tende para $\sigma$ quando o número de firmas tende para o infinito, considerando a concorrência monopolística com mercados atomistas.

Combinando (3) e (5), pode-se mostrar que os preços $\left(p_{k i j}\right)$ são funções crescentes da qualidade $\alpha_{k j}$ e função decrescente do número de variedades $n_{k i}$, ceterisparibus. Esse resultado é consequência da substituiçãoentre as variedades de um bem, como foi demonstrado em Gaulier e Méjean (2006) ${ }^{5}$, com base no efeito diferenciação, de acordo com Krugman (1980).

Segundo Crozet e Erkel-Rousse (2004), a equação de importação do produto $k$ originada do país ipara o país $j$, considerandobens diferenciados, pode ser expressa como a seguir:

$$
M_{k i j}=n_{k i} p_{k i j} y_{k i j}(7)
$$

Substituindo (4) em (7), obtemos:

$$
M_{k i j}=\left(p_{k i j} / p_{k j}\right)^{1-\sigma}\left(n_{k i} \alpha_{k i j}^{\sigma} / \sum_{i^{\prime}=1}^{I} n_{k i} \cdot \alpha_{k i^{\prime} j}^{\sigma}\right) E_{k j}
$$

Expressando as importações do país $j$ com respeito a um concorrente $i^{\prime}$, temos:

$$
M_{k i j} / M_{k i^{\prime} j}=\left(p_{k i j} / p_{k i^{\prime} j}\right)^{1-\sigma}\left(n_{k i} / n_{k i^{\prime}}\right)\left(\alpha_{k i j} / \alpha_{k i^{\prime} j}\right)^{\sigma}
$$

Transformada a equação (9) em termos de taxas de crescimento, obtemos:

$\log \left(\right.$ mshare $_{k i j I^{\prime} t}=-\left(\alpha_{p}-1\right) \log \left(\right.$ preço $\left._{k j I^{\prime} t}\right)+\alpha_{g} \log \left(\operatorname{var}\right.$ iedade $\left._{k j I^{\prime} t}\right)+\alpha_{q} \log \left(\right.$ qualidade $\left._{k j I^{\prime} t}\right)(10)$

Onde:

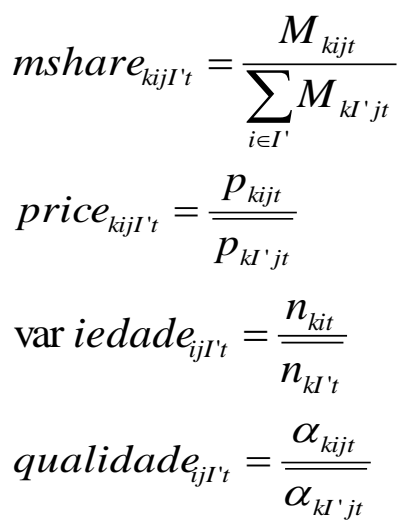

As variáveis $\overline{p_{k I^{\prime} j t}}, \overline{n_{k I^{\prime} t}}$, e $\overline{\alpha_{k I^{\prime} t}}$ representam as médias dos preços, variedade e qualidade, respectivamente, para um grupoi's de competidores pertencentes ao conjunto de parceirosI's.

mshare $_{k i j I t}$ reflete a parcela de importação de bens de um setor $k$ originada de um país exportador $i$ para um país importador $j$ ao longo do período $t$.

preço $_{k j I^{\prime} t}$ reflete o preço relativo do bem $k$ vindo do país $i$ para o país $j$;

var iedade $_{i j I_{t}}$ reflete o número de variedades do bem $k$;

qualidade $_{i j t}$ reflete a qualidade relativa do bem importado;

Esse modelo sugere que os exportadores podem tentar adquirir maior quota de mercado através de dois canais: podem reduzir seus preços em relação aos dos seus concorrentes ou fazer valer a sua força relativa através do canal de diferenciação, ou seja, podem aumentar o número de variedades oferecidas ou melhorando a qualidade de seu produto em relação à de seus concorrentes. (Zagamé, 2006).

Para chegar ao modelo testável, incluímos a variável dist $_{k i j I^{\prime} t}$, que reflete a distância relativa entre os parceiros comerciais $i$ e $j$, utilizada para representar os custos de transação. De acordo com Anderson e

\footnotetext{
${ }^{5}$ Gaulier e Méjean (2006) estudam o impacto sobre o preço agregado da importação de novas variedades numa amostra de 28 economias avançadas e de mercado emergentes e confirmam o impacto descendente de variações na variedade importada sobre o nível de preços de importação. Em média, entre 1994 e 2003, o surgimento de novas variedades conduziu a uma redução anual não registrada de 0,2 por cento nos preços de importação.
} 
Marcouiller (1999) e Rauch (1999),essa variável pode ser adicionada para controlar as barreiras ao comércio que não sejam contabilizadas através dos preços relativos.

Acrescentado também o fator constante $c_{k i j I}$, obtemos a equação a ser estimada: $\log \left(\right.$ mshare $_{k \text { kjI't }}=-\left(\alpha_{p}-1\right) \log \left(\right.$ preço $\left._{k i j I^{\prime}}\right)+\alpha_{g} \log \left(\operatorname{var}\right.$ iedade $\left.e_{k j I ' t}\right)+\alpha_{q} \log \left(\right.$ qualidade $\left._{k i I^{\prime} t}\right)$ $-e_{d} \log \left(\right.$ dist $\left._{i j I}\right)+\operatorname{Interc}+u_{k i j I t}$

Estamos interessados na elasticidade preço da demanda por importações $\alpha_{p}$, e na elasticidade da qualidade relativa $\alpha_{q}$ entre as diversas variedades do bem $k$.

Hipótese testável:

- As equações tradicionais de demanda por importação não incorporam a diferenciação dos bens e seu impacto sobre os preços, desse modo, a elasticidade preço como convencionalmente calculada apresenta um viés, pois o comportamento das variáveis não incluídas no modelo é parcialmente captado pelo coeficiente dos preços, gerando um viés. Sendo assim, o efeito negativo do preço será maior do que o previsto, pois com a introdução das novas variáveis o impacto positivo da qualidade deixa de influir no coeficiente dos preços.

\subsection{Variáveis e Dados Utilizados}

Os dados utilizados são anuais, referem-se ao período de 1996 a 2013 e consideram o conjunto dos 20 principais parceiros comerciais do Brasil. O painel assim formado está composto por 340 observações (20 países $x 17$ anos) ${ }^{6}$.

O modelo contém variáveis não observáveis ou imperfeitamente medidas, que têm de ser substituídas por proxies, a primeira delas refere-se aos preços. Como proxy foi utilizado o índice de preços para as importações, calculado segundo metodologia elaborada pela Fundação Centro de Estudos do Comércio Exterior(Funcex $)^{7}$.

Para a variável variedade serão consideradas duas proxies, a primeira delas foi sugerida por Krugman (1979), baseada na produção setorial, ou de preferência o PIB setorial. Em virtude da dificuldade em obter dados para o PIB setorial, Crozet e Erkel-Rousse (2004) sugerem uma aproximação para essa medida, os autores utilizam o PIB agregado e introduzem uma variável auxiliar, a especialização relativa ${ }^{8}$, para captar a estrutura setorial do PIB. O produto dessas duas variáveis (PIB agregado e especialização relativa) constitui uma proxy para o PIB setorial e, consequentemente, para o número de variedades.

A segunda proxysugerida na literatura para variedade é derivada da decomposição do comércio intra-indústria (CII) entre comércio intra-indústria vertical (CIIV) e comércio intra-indústria horizontal (CIIH), utilizando a metodologia de Abd-el-Rahman(1991) e Greenaway et al.(1994) ${ }^{9}$.

Para a variável qualidade foram consideradas duas proxies, a primeira está baseada na metodologia descrita acima, especificamente no índice de comércio intra-indústria vertical superior (CIIV $\mathrm{V}_{\text {sup }}$ ), a segunda se baseia na metodologia proposta por Hausmann, et. al. (2007), que classifica as mercadorias comercializadas segundo sua produtividade implícita, a partir da qual, é calculado o grau de sofisticação das cestas de bens. Para melhorar a representatividade do índice como proxy para a qualidade dos bens importados, procedemos ao ajuste para a qualidade conforme proposto por Xu (2010) ${ }^{10}$.

Os dados de importação foram coletados no banco de dados do Comtrade (Commodity Trade StatisticsDatabase) edeflacionados pelo índice de preços ao produtor americano (PPI), o PIB de cada parceirocomercial foi extraído da base de dados do World Bank (WB). Os valores referentes à variável dist $_{i j I}$, foram obtidos no Centre d'EtudesProspectives et d'InformationsInternationales (CEPII).

\footnotetext{
${ }^{6}$ Os países considerados são: China, Estados Unidos, Argentina, Alemanha, Índia, Itália, Japão, França, México, Chile, Espanha, Bolívia, Reino Unido, Rússia, Canadá, Uruguai, Bélgica, Peru, Paraguai, Venezuela.

7 Ver Anexo.

${ }^{8}$ Ver Anexo.

${ }^{9}$ Ver Anexo.

${ }^{10}$ Ver Anexo.
} 
A presente análise está baseada nos seguintes modelos: o Método de Mínimos Quadrados Empilhados (POOLED), Modelo de Efeitos Fixos ( $L S D V)$ e Efeitos Aleatórios $(M Q G)$. A estimação através de diferentes modelos econométricos é feita com o intuito de verificar a consistência dos resultados, tornando a análise mais robusta.

\section{RESULTADOS OBTIDOS}

\subsection{Análise Empírica}

Antes de apresentar os resultados, é interessante analisar acorrelação entre as variáveis do modelo.Teoricamente, espera-se que o preço e a qualidade estejam positivamente correlacionados, bem como a qualidade e o volume de importações. Com relação à variedade, espera-se que o aumento do número de variedades,ceterisparibus, leve a queda nos preços devido à maior concorrência.

Segundo Crozet e Erkel-Rousse (2004), o resultado esperado para a relação entre preço e volume de importações é mais ambíguo; se o efeito preço predomina, a correlação entre preço e quantum importado deve ser negativa, dado que preços relativamente altos representam desvantagem competitiva levando redução nas importações. Se, no entanto, a dimensão da qualidade que está implicitamente inserida no preço for dominante, o sinal dessa correlação pode ser invertido, pois preços elevados podem sinalizar que a qualidade é maior, o que segundo o autor, estimula a compra dos bens.

A Tabela 1, a seguir, apresenta a correlação entre as variáveis utilizadas no modelo.

Tabela 1: Matriz de Correlação aplicada às variáveis do modelo (1997-2013).

\begin{tabular}{|c|c|c|c|c|c|c|}
\hline \multirow{2}{*}{ Variáveis } & \multicolumn{6}{|c|}{ Manufaturados } \\
\hline & $M_{\text {manufat. }}$ & Preço & CIIV & CIIH & PRODY & PIB $_{\text {Setorial }}$ \\
\hline Mmanufat. & 1,00 & & & & & \\
\hline Preço & $-0,20$ & 1,00 & & & & \\
\hline CIIV & 0,26 & 0,02 & 1,00 & & & \\
\hline CIIH & $-0,04$ & $-0,06$ & 0,06 & 1,00 & & \\
\hline PRODY & 0,44 & 0,13 & 0,29 & 0,03 & 1,00 & \\
\hline PIB $_{\text {Setorial }}$ & $-0,07$ & $-0,06$ & 0,08 & 0,14 & $-0,01$ & 1,00 \\
\hline \multicolumn{7}{|c|}{ Básicos } \\
\hline & $M_{\text {básicos }}$ & Preço & $C I I V$ & $\mathrm{CIIH}$ & PRODY & PIB $_{\text {Setorial }}$ \\
\hline Mbásicos & 1,00 & & & & & \\
\hline Preço & $-0,31$ & 1,00 & & & & \\
\hline CIIV & $-0,16$ & 0,10 & 1,00 & & & \\
\hline CIIH & $-0,11$ & $-0,06$ & $-0,31$ & 1,00 & & \\
\hline PRODY & $-0,13$ & 0,21 & 0,29 & 0,18 & 1,00 & \\
\hline PIB $_{\text {Setorial }}$ & $-0,07$ & $-0,18$ & $-0,20$ & 0,37 & 0,03 & 1,00 \\
\hline
\end{tabular}

Fonte:Resultados obtidos pela autora com dados da pesquisa através do Programa Stata 11.0 a relação tradicional entre preço e quantum
Observando as correlações é possível perceber que a relos importador parece predominar, nos dois setores a correlação simples entre os preços relativos e importações relativas revela-se negativao que mostra que os preços tem um papel predominante nas decisões de importação do Brasil. É possível entender tal comportamento quando analisamos os principais mercados de origem das importações brasileiras, a China ${ }^{11}$ ocupa a primeira posição nessa lista, esse mercado é conhecido pela elevada competitividade via preços, o que corrobora com a alta influência dos preços como determinante das importações brasileiras. Como esperado, dada a relativa homogeneidade desses bens, a categoria de produtos básicos apresenta uma relação negativa mais forte. Para esse tipo de produto, vender a preços baixos parece exercer umpapel crucial no desempenho comercial.

Crozet e Erkel-Rousse (2004) analisam esse resultado para o conjunto de países da OCDE, e ao contrário do esperado, encontram uma relação positiva entre preço e quantum importado. Neste caso,

\footnotetext{
${ }^{11} 16,3 \%$ do total importado pelo Brasil em 2014 tiveram como origem a China.
} 
segundo os autores, o efeito positivo da qualidade predomina sobre o efeito preço negativo. Os autores mostram também que quanto maior o grau de diferenciação do produto, maior a correlação positiva entre o preço e qualidade, assim como entre preço e quantum importado, pois maiores preços sinalizam melhor qualidade.

As duas variáveis utilizadas como proxies para a qualidade (PRODY e CIIV) apresentam uma relação positiva com o quantum importado de manufaturados, já para osprodutos básicos essa correlação se mostrou negativa. Esse resultado também foi observado por outros autores, Crozet e Erkel-Rousse (2004) argumentam que os indivíduos sentem dificuldade em definir a qualidade de produtos com características mais homogêneas, em geral, nesse caso "alta qualidade" está diretamente relacionada a "preço mais baixo". Sendo assim, a correlação negativa entre qualidade e quantum importado no segmento básico pode ser consequência da correlação positiva entre qualidade e preços, pois o aumento da qualidade induz ao crescimento dos preços, isso provoca indiretamente a redução nas importações.

A correlação entre as variáveis parece não comprometer a estimação do modelo, assumindo que exista forte correlação entre variáveis para valores absolutos superiores a 0,8 , como é de costume na literatura. Para verificar se efetivamente existe a presença de multicolinearidade no modelo, foi calculado o fator de inflação da variância (FIV). Na presença de multicolinearidade severa os coeficientes podem não refletir o efeito particular da variável explicativa sobre aregressora, uma vez que o coeficiente estará contaminadopelo efeito de outras variáveis e apenas um efeito parcial lhe poderá ser atribuído. É prática na literatura considerar que existe multicolinearidade severa quando o FIV excede o valor de 5. Neste caso, o FIV foi inferior a 5 para todas as variáveis do nosso modelo. Assim, o modelo foi gerado sem a exclusão de qualquer das variáveis.

Foram estimados painéis no formato pooled (OLS), efeitos fixos (LDVS) e efeitos aleatórios (MQG), todos os modelos foram estimados com erros robustos para a heterocedasticidade. Os testes realizados foram os de Breusch-Pagan (efeitos aleatórios versus pooled) e de Hausman (efeitos aleatórios versus efeitos fixos) e apontaram para o uso do modelo com efeitos fixos. No entanto, como a significância de ambos os testes foi relativamente baixa, todos os modelos serão apresentados.

Inicialmente, estimamos a função demanda por importações para o grupo de produtos manufaturados, considerando como proxy para qualidade o índice de produtividade das importações (PRODY) ajustado para a qualidade, e o PIB setorial representando a variedade, como sugerido por Krugman (1979). Em seguida, é feita a mesma estimação, considerando a classe de produtos básicos. Posteriormente, são introduzidas novas proxies para qualidade e variedade nos dois modelos, com o objetivo de verificar a consistência dos resultados, para isso serão utilizados os índices de comércio intra-indústria vertical e horizontal.

A Tabela 2 apresenta os resultados do primeiro conjunto de estimações, considerando o conjunto de bens classificados como manufaturados. Ao estimar regressões em cada setor particular é possível eliminar a presença de heterogeneidade setorial entre os dados. Para analisar os efeitos da introdução das novas variáveis sobre o coeficiente do preço será estimado um modelo sem qualidade e outro incluindo essa variável, assim será possível analisar as alterações causadas pela inclusão da mesma.

Tabela 2: Função Demanda por Importações de Manufaturados (1997-2013).

\begin{tabular}{|c|c|c|c|c|c|c|}
\hline \multirow[b]{2}{*}{ VARIÁVEIS } & \multicolumn{2}{|c|}{ POOLED } & \multicolumn{2}{|c|}{ Efeito Fixo (LSDV) } & \multicolumn{2}{|c|}{ Efeito Aleatório (MQG) } \\
\hline & S/ Qualidade & C/ Qualidade & S/ Qualidade & C/ Qualidade & S/ Qualidade & C/ Qualidade \\
\hline \multirow[t]{2}{*}{ Elast. Preço $\left(1-e_{p}\right)$} & $-1,049$ & $-1,328$ & $-1,088$ & $-1,397$ & $-0,890$ & $-1,139$ \\
\hline & $(-4,98)^{*}$ & $(-5,95)^{*}$ & $(-4,90)^{*}$ & $(-5,95)^{*}$ & $(-8,35)^{*}$ & $(-9,54)^{*}$ \\
\hline \multirow[t]{2}{*}{$\operatorname{PRODY}\left(e_{q}\right)$} & & 0,273 & - & 0,279 & - & 0,241 \\
\hline & - & $(6,87)^{*}$ & - & $(6,80)^{*}$ & - & $(9,66)^{*}$ \\
\hline \multirow[t]{2}{*}{ PIB Setorial $\left(e_{g}\right)$} & 0,465 & 0,337 & 0,486 & 0,359 & 0,284 & 0,205 \\
\hline & $(4,22)^{*}$ & $(3,24)^{*}$ & $(4,27) *$ & $(3,36)^{*}$ & $(4,18)^{*}$ & $(3,17)^{*}$ \\
\hline \multirow[t]{2}{*}{ Distância $\left(e_{d}\right)$} & $-1,12$ & $-0,825$ & $-1,144$ & $-0,833$ & $-0,943$ & $-0,878$ \\
\hline & $(-10,51)^{*}$ & $(-7,57)^{*}$ & $(-2,39) * *$ & $(-2,46)^{* *}$ & $(-12,82)^{*}$ & $(-14,66)^{*}$ \\
\hline Constante & $-17,35$ & $-17,13$ & 16,25 & $-17,54$ & $-14,08$ & $-16,11$ \\
\hline
\end{tabular}




\begin{tabular}{l|cc|cc|cc} 
& $(-10,26)^{*}$ & $(-10,92)^{*}$ & $(-12,11)^{*}$ & $(-10,77)^{*}$ & $(-15,15)^{*}$ & $(-17,80)^{*}$ \\
$\begin{array}{l}\text { Dummy por país elou } \\
\text { tempo }\end{array}$ & & & & & & \\
$R^{2}$ Ajustado & sim & $\operatorname{sim}$ & $\operatorname{sim}$ & $\operatorname{Sim}$ & $\operatorname{sim}$ & $\operatorname{sim}$ \\
$N^{o}$ de Obs & 0,31 & 0,41 & 0,35 & 0,44 & 0,39 & 0,45 \\
& 340 & 340 & 340 & 340 & 340 & 340 \\
\hline
\end{tabular}

Fonte: Resultados obtidos pela autora com dados da pesquisa através do Programa Stata 11.0 . . *Estatisticamente significante a $1 \%$, ** estatisticamente significante a 5\%, *** estatisticamente significante a 10\%, NS não significante estatisticamente.

Ocoeficiente do preço relativo $\left(l-e_{p}\right)$ tem uma relação negativa e significante com as importações relativas em todos os modelos estimados. O preço relativo considerado é o preço do bem importado em relação ao preço do bem concorrente. Portanto, de acordo com esses resultados, se o preço do bem importado originado do país $j$ formaior do que o preço médio do bem importado do país $i$, os consumidores preferem comprar de $i$.

O comportamento das importações de manufaturados em relação ao preço se mostrou elástico, onde a variação de $1 \%$ nos preços acarreta uma variação de aproximadamente $1 \%$ no quantum importado, considerando as estimações sem qualidade. Após adicionarmos a nova variável, o coeficiente dos preços teve aumento de aproximadamente $0,3 \%$.

Segundo sugere Krugman (1980), espera-se que o coeficiente associado àproxy da variedade seja igual à unidade ou, pelo menos inferior, segundo Crozet e Erkel-Rousse (2004). Os resultados referentes ao coeficiente do PIB setorial estão de acordo com a teoria, pois a variável em questão apresentou valores positivos e inferiores a um em todos os modelos estimados, nota-se também que após a introdução da proxy para qualidade seu coeficiente foi reduzido em todos as estimações.

A variável distância, como esperado, varia negativamente com os fluxos de comércio. Como distâncias mais longas aumentam os custos de transporte, os países tendem a negociar mais com os países vizinhos. Assim, a distância entre os parceiros comerciais mostrou ser uma variável importante na determinação dos fluxos de comércio.

A Tabela 3, a seguir, apresenta os resultados da estimação considerando o grupo de produtos básicos.

Tabela 3: Função Demanda por Importações de Produtos Básicos (1997-2013)

\begin{tabular}{|c|c|c|c|c|c|c|}
\hline \multirow[b]{2}{*}{ VARIÁVEIS } & \multicolumn{2}{|c|}{ POOLED } & \multicolumn{2}{|c|}{ Efeito Fixo (LSDV) } & \multicolumn{2}{|c|}{ Efeito Aleatório (MQG) } \\
\hline & S/ Qualidade & C/ Qualidade & S/ Qualidade & C/ Qualidade & S/ Qualidade & C/ Qualidade \\
\hline \multirow{2}{*}{ Elast. Preço $\left(1-e_{p}\right)$} & $-0,64$ & $-0,74$ & $-0,84$ & $-0,83$ & $-0,76$ & $-0,64$ \\
\hline & $(-3,37)^{*}$ & $(-3,84)^{*}$ & $(-8,19)^{*}$ & $(-8,03)^{*}$ & $(-7,30)^{*}$ & $(-6,09) *$ \\
\hline \multirow{2}{*}{$\operatorname{PRODY}\left(e_{q}\right)$} & - & $-0,07$ & - & $-0,01$ & - & $-0,06$ \\
\hline & - & $(-2,72)^{*}$ & - & $(-0,31)^{N S}$ & - & $(-4,62) *$ \\
\hline \multirow{2}{*}{ PIB Setorial $\left(e_{g}\right)$} & 0,08 & 0,07 & $-0,03$ & $-0,02$ & $-0,11$ & $-0,07$ \\
\hline & $(1,04)^{N S}$ & $(0,95)^{N S}$ & $(-0,61)^{N S}$ & $(-0,54)^{N S}$ & $(-1,13)^{* *}$ & $(-1,07) * * *$ \\
\hline \multirow{2}{*}{$\operatorname{Distância~}\left(e_{d}\right)$} & $-0,43$ & $-0,42$ & $-1,12$ & $-1,14$ & $-0,36$ & $-0,31$ \\
\hline & $(-3,80)^{*}$ & $(-3,78)^{*}$ & $(1,89)^{N S}$ & $(-2,35)^{* * *}$ & $(-3,21)^{*}$ & $(-4,10) *$ \\
\hline \multirow[t]{2}{*}{ Constante } & $-7,67$ & $-6,75$ & $-4,12$ & $-5,63$ & $-3,93$ & $-4,05$ \\
\hline & $(-4,85)^{*}$ & $(-4,22)^{*}$ & $(-4,61)^{*}$ & $(-5,56)^{*}$ & $(-5,33)^{*}$ & $(-5,39)^{*}$ \\
\hline Dummy por país elou tempo & $\operatorname{sim}$ & $\operatorname{sim}$ & $\operatorname{sim}$ & $\operatorname{sim}$ & $\operatorname{sim}$ & $\operatorname{sim}$ \\
\hline$R^{2}$ Ajustado & 0,42 & 0,50 & 0,56 & 0,64 & 0,36 & 0,43 \\
\hline$N^{o}$ de Obs & 340 & 340 & 340 & 340 & 340 & 340 \\
\hline
\end{tabular}

Fonte: Resultados obtidos pela autora com dados da pesquisa através do Programa Stata $11.0 \ldots$ *Estatisticamente significante a $1 \%$,** estatisticamente significante a $5 \%$, *** estatisticamente significante a $10 \%$, NS não significante estatisticamente.

Os resultados mostram que o efeito dos preços sobre esse grupo de produtos é menor quando comparado ao grupo de bens manufaturados. Essa característica da elasticidade preço para esse segmento 
pode ser explicada pelo maior grau de dependência da importação desses bens para a economia, neste caso, as variações no preço terão um efeito menor sobre o quantum importado. Por outro lado, no caso do grupo de bens manufaturados há importação de bens menos essências, assim a variação na demanda pelos mesmos em virtude de uma alteração nos preços poderá ser maior.

O impacto da variável qualidade das importações é alterado quando consideramos bens homogêneos, como é o caso dos produtos básicos. Os coeficientes da variável PRODY foram negativos em todas as estimações e não significativos para efeitos fixos, esses resultados corroboram com os resultados encontrados para a correlação simples entre as variáveis e estão de acordo com Crozet e ErkelRousse (2004). Segundo os autores, no caso de bens homogêneos, quanto menor o preço mais atrativo será o mercado de origem das importações, pois o importador entende "alta qualidade" como equivalente a "baixo preço". Como em nosso modelo alta qualidade leva a um preço mais alto, pois a correlação entre PRODY e preço foi positiva para a categoria de produtos básicos, a alta qualidade acaba exercendo impacto negativo sobre as importações desse segmento ${ }^{12}$.

A introdução da proxy para a qualidade não causou variação significativa nas elasticidades preço, o PIB setorial não apresentou o sinal esperado em alguns casos e seu coeficiente foi estatisticamente insignificante na maior parte dos modelos estimados. Por fim, a distância apresentou o sinal esperado, no entanto, teve um impacto inferior quando comparado ao modelo com bens manufaturados.

A fim de verificar a consistência dos resultados o modelo foi estimado utilizando novas proxies para a variável qualidade e variedade, onde foi utilizado o índice de comércio intra-indústria decomposto em vertical e horizontal, os resultados para o segmento de manufaturados são apresentados na Tabela 4, a seguir.

Tabela 4: Função Demanda por Importações de Produtos Manufaturados com novas proxiespara qualidade (1997-2013).

\begin{tabular}{|c|c|c|c|c|c|c|}
\hline \multirow[b]{2}{*}{ VARIÁVEIS } & \multicolumn{2}{|c|}{ POOLED } & \multicolumn{2}{|c|}{ Efeito Fixo (LSDV) } & \multicolumn{2}{|c|}{ Efeito Aleatório (MQG) } \\
\hline & S/ Qualidade & C/ Qualidade & S/ Qualidade & C/Qualidade & S/ Qualidade & C/ Qualidade \\
\hline \multirow{2}{*}{ Elast. Preço $\left(1-e_{p}\right)$} & $-1,52$ & $-1,55$ & $-1,61$ & $-1,65$ & $-1,41$ & $-1,54$ \\
\hline & $(-6,24)^{*}$ & $(-6,15)^{*}$ & $(-6,23)^{*}$ & $(-6,14)^{*}$ & $(-6,02)^{*}$ & $(-6,34)^{*}$ \\
\hline \multirow[t]{2}{*}{$\operatorname{CIIV}\left(e_{q}\right)$} & - & 0,588 & - & 0,593 & - & 0,12 \\
\hline & - & $(2,26) * *$ & - & $(2,20)^{* *}$ & - & $(1,07)^{N S}$ \\
\hline \multirow[t]{2}{*}{$C I I H\left(e_{g}\right)$} & 0,22 & 0,19 & 0,25 & 0,15 & 0,55 & 0,55 \\
\hline & $(3,50)^{*}$ & $(3,03)^{*}$ & $(3,42)^{*}$ & $(6,95)^{*}$ & $(7,96)^{*}$ & $(7,32)^{*}$ \\
\hline \multirow[t]{2}{*}{ Distância $\left(e_{d}\right)$} & $-1,15$ & $-0,97$ & $-1,10$ & $-0,89$ & $-0,93$ & $-0,84$ \\
\hline & $(-4,63) *$ & $(-4,70) *$ & $(2,46) * *$ & $(2,50) * *$ & $(-7,51)^{*}$ & $(-7,37)^{*}$ \\
\hline \multirow[t]{2}{*}{ Constante } & $-20,06$ & $-19,92$ & $-21,68$ & $-17,69$ & $-12,02$ & $-19,79$ \\
\hline & $(-26,38)^{*}$ & $(25,69)^{*}$ & $(-28,51)^{*}$ & $(-22,35)^{*}$ & $(-13,44)^{*}$ & $(-63,09) *$ \\
\hline Dummy por país elou tempo & $\operatorname{sim}$ & Sim & $\operatorname{sim}$ & $\operatorname{sim}$ & $\operatorname{sim}$ & $\operatorname{sim}$ \\
\hline$R^{2}$ Ajustado & 0,44 & 0,50 & 0,52 & 0,60 & 0,36 & 0,47 \\
\hline$N^{o}$ de Obs & 340 & 340 & 340 & 340 & 340 & 340 \\
\hline
\end{tabular}

Fonte: Resultados obtidos pela autora com dados da pesquisa através do Programa Stata $11.0 \ldots$ *Estatisticamente significante a $1 \%$, ** estatisticamente significante a $5 \%$, *** estatisticamente significante a $10 \%$, NS não significante estatisticamente.

Os resultados estão de acordo com as estimativas encontradas com as outras proxiespara o grupo de manufaturados, a elasticidade preço foi negativa em todos os modelos, porém os preços apresentam um impacto maior sobre as importações relativas, uma variação de $1 \%$ nos preços reduz as importações relativas de manufaturados em aproximadamente $1,5 \%$.

A nova variável considerada como proxy para a qualidade teve impacto positivo sobre as importações relativas, além disso, seu coeficiente apresentou um valor maior comparado ao primeiro modelo utilizando a $P R O D Y$; no entanto, os coeficientes mostram uma significância menor. A introdução

\footnotetext{
12 Ver Tabela 1.
} 
da proxy para a qualidade reduziu os coeficientes de elasticidade como no modelo anterior; no entanto, a variação provocada no coeficiente dos preços foi bem menor. Considerando a nova proxy para variedade,os coeficientes foram menores exceto para o método de efeitos aleatórios, mas continuam positivos e significativos. A Tabela 5 a seguir, apresenta os resultados para os produtos básicos.

Tabela 5: Função Demanda por Importações de Produtos Básicos com novas proxies para qualidade

(1997-2013).

\begin{tabular}{|c|c|c|c|c|c|c|}
\hline \multirow[b]{2}{*}{ VARIÁVEIS } & \multicolumn{2}{|c|}{ POOLED } & \multicolumn{2}{|c|}{ Efeito Fixo (LSDV) } & \multicolumn{2}{|c|}{ Efeito Aleatório (MQG) } \\
\hline & S/ Qualidade & C/ Qualidade & S/ Qualidade & C/Qualidade & S/ Qualidade & C/Qualidade \\
\hline \multirow{2}{*}{ Elast. Preço $\left(1-e_{p}\right)$} & $-0,508$ & $-0,504$ & $-0,558$ & $-0,555$ & $-0,577$ & $-0,608$ \\
\hline & $(-2,53)^{*}$ & $(-2,52)^{*}$ & $(-2,61)^{*}$ & $(-2,61)^{*}$ & $(-3,75)^{*}$ & $(-3,85)^{*}$ \\
\hline \multirow[t]{2}{*}{$\operatorname{CIIV}\left(e_{q}\right)$} & - & $-0,022$ & - & $-0,021$ & - & $-0,05$ \\
\hline & - & $(-1,67)^{* * *}$ & - & $(-1,18)^{N S}$ & - & $(-0,54) * * *$ \\
\hline \multirow[t]{2}{*}{$C I I H\left(e_{g}\right)$} & 0,213 & 0,184 & 0,217 & 0,188 & 0,198 & 0,208 \\
\hline & $(4,24) *$ & $(3,47)^{*}$ & $(4,20)^{*}$ & $(3,45)^{*}$ & $(6,48) *$ & $(6,32) *$ \\
\hline \multirow[t]{2}{*}{ Distância $\left(e_{d}\right)$} & $-0,49$ & $-0,473$ & $-1,198$ & $-1,281$ & $-0,374$ & $-0,345$ \\
\hline & $(-5,48) *$ & $(-5,27)^{*}$ & $(-1,82)^{* *}$ & $(-1,92)^{* *}$ & $(-6,69) *$ & $(-6,77)^{*}$ \\
\hline \multirow[t]{2}{*}{ Constante } & $-6,96$ & $-6,84$ & $-6,92$ & $-6,81$ & $-6,08$ & $-6,06$ \\
\hline & $(-9,43)^{*}$ & $(-9,23) *$ & $(-8,75)^{*}$ & $(-8,60) *$ & $(-12,76)^{*}$ & $(-12,85)^{*}$ \\
\hline Dummyporpaís elou tempo & $\operatorname{sim}$ & $\operatorname{sim}$ & $\operatorname{sim}$ & Sim & $\operatorname{sim}$ & $\operatorname{sim}$ \\
\hline$R^{2}$ Ajustado & 0,35 & 0,44 & 0,43 & 0,55 & 0,29 & 0,34 \\
\hline$N^{o} d e O b s$ & 340 & 340 & 340 & 340 & 340 & 340 \\
\hline
\end{tabular}

Fonte: Resultados obtidos pela autora com dados da pesquisa através do Programa Stata $11.0 \ldots$ *Estatisticamente significante a $1 \%$,** estatisticamente significante a $5 \%, * * *$ estatisticamente significante a $10 \%$, NS não significante estatisticamente.

Os resultados para o segmento de produtos básicos seguiram a mesma tendência do modelo apresentado na Tabela 3, as elasticidades preço continuam menores que no modelo para bens manufaturados, e o impacto da nova proxy para a qualidade sobre as importações relativas foi negativo e não significativo. Não havendo variação significativa nos coeficientes dos preços após a introdução da proxy para a qualidade.

No geral, pode-se perceber que os resultados utilizando as novas proxies para a qualidade e variedade foram consistentes, o impacto de cada variável representativa foi mantido, no entanto, a variável $P R O D Y$ apresentou um maior nível de significância.

Com base nos resultados apresentados, foi possível mostrar que houve um aumento na elasticidade preço ao adicionar qualidade mostrando-se compatível com os resultados de Crozet e Erkel-Rousse (2004) e Zagamé, et. al (2005), mas apenas no segmento de bens manufaturados. Segundo os autores, isso ocorre porque nos modelos que excluema qualidade, o coeficiente relativo do preço leva em conta um efeito preço puro (que é negativo) somado ao efeito positivo indireto da qualidade do produto nas importações relativas, desse modo a soma dos dois efeitos reduz ${ }^{13}$ o real impacto dos preços. Quando a qualidade é levada em conta, o seu coeficiente capta esse efeito indireto, o qual desaparece do coeficiente do preço corrigindo seu viés.

Nos trabalhos da literatura internacional quando a proxy da qualidadeé excluída do modelo, como é o caso na maioria dos trabalhos empíricos sobre equações de demanda por importações, vários problemas aparecem.A elasticidade preço estimada cai significativamente abaixo da unidade, seja qual for o modelo. No caso brasileiro a elasticidade preço está acima de um em todos os modelos com bens manufaturados, com e sem qualidade; embora a introdução da mesma eleve os coeficientes de elasticidade, o impacto da introdução da qualidade é menos relevante do que nos modelos aplicados a outros países, o que parece mostrar que para a economia brasileira o preço tem um papel mais importante que a qualidade como determinante dos fluxos de comércio. O mesmo ocorre com a demanda por

\footnotetext{
${ }^{13}$ Considerando o valor absoluto.
} 
produtos básicos, as elasticidades preço foram menores que a unidade, mas ao contrário da literatura internacional, a inclusão da nova variável não mostrou efeito significativo.

Note-se que a introdução da proxy para a qualidade induz à queda nos coeficientes da variedade, na maior parte dos modelos com coeficientes significativos. De fato, nas equações excluindo qualidade, os coeficientes das proxies para a variedade abrangem o efeito direto da variedade mais o efeito indireto da qualidade, dado que a mesma não foi introduzida explicitamente no modelo, assim como ocorreu em alguns casos com o preço. A introdução da qualidade na equação retira esse efeito dos coeficientes da variedade.

A distância entre as capitais foi usada como proxy para os custos do comércio entre dois países. Conforme esperado, a variável distância apresentou sinal negativo em todos os modelos estimados, confirmando a proposição de que quanto mais distantes os países maiores serão os custos incorridos no comércio.

A Tabela 6, a seguir, apresenta algumas estimativas realizadas naliteratura nacional sobre a elasticidade preço das importações. Percebe-se que há uma grande variabilidade metodológica. Alguns autores desagregam suas estimativas para diversos setores ou por categorias de uso como Zini (1988), Castro e Cavalcanti (1997) e Carvalho e Parente (1999), mas a maior parte da literatura apresenta uma análise agregada, como neste último caso a comparação seria ainda mais difícil, apresentamos só dois desses casos.

Tabela 6: Estimativas de elasticidade preço da demanda por importações realizadas para o Brasil.

\begin{tabular}{|c|c|c|c|c|c|c|c|}
\hline Autores & $\begin{array}{l}\text { Nível de } \\
\text { Agregação }\end{array}$ & Período & $\begin{array}{l}\text { Fluxo de } \\
\text { Comércio }\end{array}$ & $\begin{array}{c}\text { Tipo de } \\
\text { Equação }\end{array}$ & $\begin{array}{l}\text { Índice de } \\
\text { Preços }\end{array}$ & $\begin{array}{c}\text { Nível de } \\
\text { desagregação }\end{array}$ & Elasticidade Preço \\
\hline Dib (1985) & Agregadas & & & & \begin{tabular}{|l|} 
Custo Real \\
Efetivo das \\
Importações \\
(considera o \\
preço \\
internacional \\
das \\
importações, \\
taxa de câmbio \\
real e Îndice \\
de tarifa) \\
\end{tabular} & & CP:-1,05; LP: $-1,76$ \\
\hline Zini (1988) & & $\begin{array}{l}\text { 1970-1986 } \\
\text { Trimestral }\end{array}$ & Bilateral & $\begin{array}{l}\text { Função } \\
\text { Demanda } \\
\text { por } \\
\text { Importações } \\
\end{array}$ & & $\begin{array}{l}\text { Por setor de } \\
\text { Atividade }\end{array}$ & $\begin{array}{l}\text { Industrializados: }-1,85 \text {. } \\
\text { Agrícolas:- } 0,43 \text {; } \\
\text { Minerais: }-0,05\end{array}$ \\
\hline $\begin{array}{l}\text { Castro e } \\
\text { Cavalcanti } \\
\text { (1997) }\end{array}$ & $\begin{array}{l}\text { Por categoria } \\
\text { de Uso }\end{array}$ & $\begin{array}{l}\text { 1955-1995 } \\
\text { Anual }\end{array}$ & Bilateral & $\begin{array}{l}\text { Função } \\
\text { Demanda } \\
\text { por } \\
\text { Importações }\end{array}$ & Câmbio Real & & $\begin{array}{l}\text { Import. Totais:-0,45; } \\
\text { Bens de Capital:- } \\
\text { 0,56;Bens } \\
\text { Intermediários:-0,55; } \\
\text { Bens de Consumo:- } 0,49\end{array}$ \\
\hline $\begin{array}{l}\text { Carvalho e } \\
\text { Parente } \\
\text { (1999) }\end{array}$ & $\begin{array}{l}\text { Por categoria } \\
\text { de Uso }\end{array}$ & $\begin{array}{l}\text { 1978-1996 } \\
\text { Mensal }\end{array}$ & Bilateral & $\begin{array}{l}\text { Modelo de } \\
\text { Substituição } \\
\text { Imperfeita } \\
\text { (Longo } \\
\text { Prazo) } \\
\end{array}$ & Câmbio Real & & $\begin{array}{l}\text { Bens de Capital:- } \\
\text { 1,9;Intermediários:- } \\
\text { 2;Não Duráveis:-1,4: } \\
\text { Duráveis:-2,9; } \\
\text { Combustíveis:-0,56. }\end{array}$ \\
\hline $\begin{array}{l}\text { Carvalho e } \\
\text { De Negri } \\
(2000)\end{array}$ & $\begin{array}{l}\text { Grupo de } \\
\text { Produtos } \\
\text { Agropecuários }\end{array}$ & $\begin{array}{l}(1977-1998) \\
\text { Trimestral }\end{array}$ & Bilateral & $\begin{array}{l}\text { Modelo de } \\
\text { Substituição } \\
\text { Imperfeita }\end{array}$ & $\begin{array}{l}\text { Índices de } \\
\text { Preços dos } \\
\text { Produtos } \\
\text { Agropecuários } \\
\text { (FGV) }\end{array}$ & $\begin{array}{l}\text { Painel } \\
\text { desagregados } \\
\text { por indústria }\end{array}$ & $-1,342$ \\
\hline $\begin{array}{l}\text { Skiendziel } \\
\text { (2008) }\end{array}$ & $\begin{array}{l}\text { Dados } \\
\text { Agregados }\end{array}$ & $\begin{array}{l}\text { 1991-2007 } \\
\text { Trimestral }\end{array}$ & Bilateral & & \begin{tabular}{|l|} 
Índices de \\
Preços das \\
Importações \\
(Funcex) \\
\end{tabular} & & CP:-0,11; LP:-0,55 \\
\hline $\begin{array}{l}\text { Santos, et. } \\
\text { al.(2009) }\end{array}$ & Agregadas & $1992-1997$ & Bilateral & $\begin{array}{l}\text { Função } \\
\text { Demanda } \\
\text { por } \\
\text { Importações } \\
\end{array}$ & Câmbio Real & & Entre $-0,39$ e $-0,44$ \\
\hline $\begin{array}{l}\text { Kawamoto, } \\
\text { et. al. (2013) }\end{array}$ & $\begin{array}{l}\text { Grupo de } \\
\text { Produtos } \\
\text { Manufaturados, } \\
\text { agregados por } \\
\text { códigos CNAE. }\end{array}$ & $\begin{array}{l}\text { 2003-2010 } \\
\text { Mensal }\end{array}$ & Bilateral & $\begin{array}{l}\text { Modelo de } \\
\text { Thirlwall } \\
\text { (1979) }\end{array}$ & $\begin{array}{l}\text { Índices de } \\
\text { Preços das } \\
\text { Importações } \\
\text { (Funcex) }\end{array}$ & $\begin{array}{l}\text { Painel } \\
\text { desagragado } \\
\text { por categoria } \\
\text { da Indústria de } \\
\text { Transformação } \\
\end{array}$ & $\begin{array}{l}\text { Entre }-0,08 \text { e }-0,19 \text {, } \\
\text { dependendo do modelo. }\end{array}$ \\
\hline
\end{tabular}

No trabalho de Zini (1988)eCarvalho e Parente (1999), os setores menos diferenciados apresentaram elasticidades preço maiores, corroborando com os resultados obtidos no presente estudo, 
onde os setores básicos mostraram elasticidade preço menor. O mesmo não ocorre em Castro e Cavalcanti (1997), onde os resultados mostram pouca variabilidade entre os setores.

Quando se consideram estimações agregadas (Dib (1985), Skiendziel (2008) e Santos, et. al.(2009)), percebe-se que as mesmas apresentam valores relativamente baixos; nestes casos, a comparação é bem mais difícil, pois os estudos não levam em conta a heterogeneidade setorial.

No trabalho de Carvalho e deDe Negri (2000), as elasticidades são calculadas para o setor agropecuário, supondo uma economia pequena. Seus resultados mostram uma elasticidade de aproximadamente $1,34 \%$. Esse valor está bem acima dos encontrados em outros trabalhos paraprodutos básicos; no entanto, estão mais próximos das estimativas do presente estudo.

No geral, percebe-se que os resultados dos autores supracitados apresentam comportamentos similares quando se estimam funções desagregadas, os setores menos diferenciados mostram elasticidades preço inferiores,já as estimativas agregadas revelam valores menores. Deve-se ressaltar novamente, que essas estimativas não são diretamente comparáveis, pois há uma grande variabilidade nos procedimentos metodológicos utilizados pelos autores. A literatura internacional sobre elasticidade é vasta; no entanto, como já mencionado, a comparação direta é ainda mais difícil, em virtude da variabilidade de modelos e especificidades de cada economia.

Uma comparação mais direta pode ser feita com estimações utilizando modelos similares; no entanto, não há conhecimento de aplicação das mesmas para a economia brasileira. A literatura base para o presente trabalho ainda é escassa mesmo internacionalmente, mesmo assim é possível comparar mais adequadamente os resultados, embora tenham diferentes formas de tratamento dos dados e métodos de estimação.

$\mathrm{Na}$ Tabela 7, a seguir, são apresentados alguns resultados obtidos na literatura internacionalque fazem uso de modelos semelhantes ao utilizado no presente estudo. Pode-se observar que os mesmos seguiram um padrão similar, no entanto, suas estimativas se mostraram mais consistentes, o que está em parte relacionado à melhor qualidade e quantidade de dados disponibilizados nas regiões onde os mesmos foram aplicados, permitindo estimativas mais precisas e confiáveis.

Tabela 7: Função Demanda por Importações a nível Internacional.

\begin{tabular}{|c|c|c|c|c|c|c|c|c|c|c|c|c|}
\hline \multirow{3}{*}{ Método de Estimação } & \multicolumn{4}{|c|}{ Erkel-Rousse e Gallo (2002) } & \multicolumn{4}{|c|}{ Crozet e Erkel-Rousse (2004) } & \multicolumn{4}{|c|}{ Zagamé, et al. (2005) } \\
\hline & \multicolumn{2}{|c|}{ Sem Qualidade } & \multicolumn{2}{|c|}{ Com Qualidade } & \multicolumn{2}{|c|}{ Sem Qualidade } & \multicolumn{2}{|c|}{ Com Qualidade } & \multicolumn{2}{|c|}{ Sem Qualidade } & \multicolumn{2}{|c|}{ Com Qualidade } \\
\hline & $O L S$ & $2 S L S$ & $O L S$ & $2 S L S$ & $O L S$ & $2 S L S$ & $O L S$ & $2 S L S$ & $O L S$ & $2 S L S$ & $O L S$ & $2 S L S$ \\
\hline $\operatorname{Preço~}(1-\sigma)$ & 0,25 & 0,24 & $-0,03$ & $-0,23$ & 0,06 & 0,22 & $-0,15$ & $-0,16$ & $-0,11$ & $-0,15$ & $-0,6$ & $-0,91$ \\
\hline Qualidade & - & - & 0,28 & 0,42 & - & - & 0,22 & 0,23 & - & - & 1,18 & 1,21 \\
\hline
\end{tabular}

Fonte:Elaborado pela autora.

Erkel-Rousse e Gallo (2002), utilizando um modelo similar para um conjunto de doze países da OCDE, encontram uma elasticidade preço deaproximadamente 0,25 , sem a introdução no modelo da proxy para qualidade. Ao introduzi-lo, esse valor passa a variar no intervalo de $-0,03$ e $-0,23$, dependendo do modelo considerado. Pode-se ver quea elasticidade apresentou um valor positivo antes da introdução da proxy, segundo o autor, esse comportamento é resultado da forte influência da qualidade sobre a demanda por importações nos países mais desenvolvidos, quando não inserida explicitamente o efeito da qualidade é em parte somado ao efeito negativo do preço, neste caso, esse efeito foi tão expressivo que superou o impacto negativo dos preços. O coeficiente da qualidade variou entre 0,28 e 0,42.

Os resultados de Crozet e Erkel-Rousse (2004) com dados agregados considerando quatro maiores países da UE (França, Alemanha, Itália, Reino Unido) também mostraram valor positivo para a elasticidade preço das importações antes da introdução de uma proxy para a qualidade, situando entre 0,06 e 0,22.Com a introdução da qualidade esses valores passam para $-0,15$ e $-0,16$, dependendo do modelo considerado.O coeficiente da qualidade foi de aproximadamente 0,20 nos modelos estimados.

Na mesma linha do trabalho anterior, Zagamé, et al. (2005), estimam o impacto da introdução da qualidade no modelo de demanda por importações da Europa utilizando um painel mais robusto e confirma os resultados obtidos por Erkel-Rousse e Gallo (2002);no entanto, o impacto da qualidade foi maior, em torno de 1,20. O trabalho conclui que a qualidade é importante para o comércio, especialmente para os produtos diferenciados. 
Comparando esses resultados com os encontrados nesse trabalho, observa-se que o impacto da qualidade é menor, principalmente no segmento básico. A introdução da nova variável não tem impacto significativo nas elasticidades preço como ocorre com os resultados apresentados na Tabela 7; o que parece mostrar que a demanda por importações brasileiras é determinada principalmente pelos preços.

Os resultados apresentados acima se referem à economias desenvolvidas, onde seus produtos apresentam em geral, uma qualidade superior; pois sua competitividade está em grande parte baseada na qualidade de seus bens. Nesses países a qualidade tem peso maior, quando comparada aos resultados de países em desenvolvimentos como é o caso Brasil, onde os preços parecem ter um papel mais importante.

Esse resultado também pode ser confirmado quando analisamos os parceiros comerciais do Brasil. A principal origem das importações brasileiras é a China, uma economia conhecida pela sua expressiva competitividade via preços e não via qualidade, o que nos leva a concluir que as importações brasileiras originadas desse país são determinadas basicamente pelo preço.

De fato, estamos no campo da suposição, mas parcialmente embasados nos resultados obtidos. Há significativas limitações, principalmente no que se refere à variável qualidade. Como já mencionado, trata-se de uma variável pouca precisa, pois possui elementos subjetivos que dificilmente serão captados. Para se afirmar com mais certeza as proposições acima, seria preciso uma análise mais desagregada por setores e por país, bem como a utilização de melhores proxiespara as variáveis.

\section{CONCLUSÕES}

Neste artigoforam estimadas equações de demanda por importações utilizandoproxies para a qualidade dos produtos, com o objetivo deavaliar seu impacto sobre as elasticidades preço das importações brasileiras. Segundo a literatura, as elasticidades preço no comércio internacional são frequentemente subestimadas e a correção desse viés é feita quando se considera os efeitos da qualidade no modelo, isso pode ajudar a estimar "corretamente" os "verdadeiros" valores das elasticidades.

Ao considerar o papel da qualidade como um dos determinantes da demanda por importações relativas do Brasil, foi verificado que seu impacto sobre as importações de bens manufaturados é positivo e significante, já para o conjunto de produtos básicos a variável apresentou um coeficiente negativo e insignificante na maioria das estimações.

Os coeficientes para os preços obtidos foram ao encontro dos resultados obtidos a nível internacional por Crozet e Erkel-Rousse (2004), principalmente para as importações de produtos manufaturados, neste caso a variação na elasticidade preço das importações foi maior depois da introdução de uma proxy para qualidade.

Comparando os resultados obtidos neste trabalho com a literatura internacional foi possível observar que a demanda por importações brasileiras é mais influenciada pelos preços do que pela qualidade, já nos países mais desenvolvidos a qualidade tem papel mais importante nas decisões de importação, e isso é mostrado pela significativa variação que a introdução da proxy para a qualidade causa nas elasticidades preço.

Apesar de comparativamente menor, a qualidade parece ter um papel importante na determinação dos fluxos de comércio brasileiro, mas esse poderá ser limitado pela influência dos preços, pois se o aprimoramento da qualidade levar a aumentos significativos do preço, o impacto positivo da qualidade será diluído pela forte influência negativa dos preços.

Embora o debate sobre a magnitude da elasticidade preço estar longe de terminar, o presente trabalho tornou evidente certas peculiaridades do caso brasileiro, como a supremacia dos preços como determinante dos fluxos de importação, bem como a reduzida importância das novas variáveis sobre a demanda por bens de menor processamento industrial.

Deve-se resaltar que o presente trabalho apresenta várias limitações que impedem a obtenção de estimativas mais precisas e confiáveis; tal problema é citado pela literatura em geral que trabalha com variáveis pouco precisas, como a qualidade. Para essa variável, não há medidas diretamente observáveis, o que nos leva a construção de proxies para a mesma, ainda assim, há elementos subjetivos que dificilmente serão capturados. Essa limitação deve ser levada em conta nos resultados obtidos.

Mesmo diante das limitações, os resultados mostraram-se coerentes e suscitam a necessidade de aperfeiçoamento nos modelos sobre comércio. A estimação incorreta das elasticidades do comércio 
compromete a correta avaliação das implicações depolíticas comerciais sobre uma economia, gerando assim, medidas incapazes de atingir os objetivos desejados.

\section{REFERÊNCIAS BIBLIOGRÁFICAS}

Abd-el-Rahman, K. Firms Competitive and National Comparative Advantages as Joint Determinants of Trade Composition. Working Paper, 127, 83-97, 1991.

Aiginger, K . The Use of Unit Values for Evaluating the Competitiveness of Nations, Conceptual Issues and An Application for Germany, Austrian Institute of EconomicResearch and University of Linz, pg 23, 1995.

Aiginger, K. The Use of Unit Values to Discriminate between Price and Quality Competition, Cambridge Journal of Economics, Vol 25(5), September 1997A, pg 571-592, 1997.

Aiginger, K.A Framework for Evaluating the Dynamic Competitiveness of Countries, Structural Change and Economic Dynamics, Cambridge Journal of Economics, Vol 25(5), September 1997B, pg 159-188, 1997.

AigingerK . "Measuring the Intensity of Quality Competition in Industries", WIFO Quaterly 2001/1.

Anderson, J. e Marcouiller, D. Trade, Insecurity and home bias, NBER Working paper, 1999.

Anderton B. Innovation, product quality, variety, and trade performance: an empirical analysis of Germany and the UK.Oxford Economic Papers, 48. pp.152-167, 1998.

Armington, Paul S., "A Theory of Demand for Products Distinguished by Place of Production,"'IMF Staff Papers. pp.78-159, 1969.

Bergstrand J.H. "The Generalized Gravity Equation in Monopolistic Competition and the Factor

Proportions Theory in International Trade", Review of Economic and Statistics, Vol 71, pg 143-153,

1989.

Brülhart, M.; Elliott, R. J. R. Labour-market effects of intra-industry trade: evidence for the United

Kingdom. WeltwirtschaftlichesArchiv, 138(2), p. 207-228, 2002

Castro, A.; Cavalcanti, M. A. "Estimação de Equações de Exportação e Importação para o Brasil 1955/95." Pesquisa e Planejamento Econômico 28 (1): 1-68, 1998.

Castro, A.; Cavalcanti, M. A. "Estimação de Equações de Exportação e Importação para o Brasil 1955/95. Texto para Discussão n. 469, IPEA, Rio de Janeiro,1997.

Carvalho, A; De Negri , J. Estimação de equações de importação e exportação de produtos agropecuários para o Brasil: (1977/1998) Texto para Discussãon. 698,IPEA, Rio de Janeiro, 2000.

CARVALHO, A., PARENTE, M., LERDA, S., MIYATA, S. Impactos da integração comercial Brasil Estados Unidos. Brasília: Texto para Discussãon. 646, IPEA, 1999.

Crozet, M; Erkel-Rousse, H . Trade Performances, Product Quality Perceptions, and the Estimation of Trade Price Elasticities. Review of International Economics. 12(1), 108-129, 2004.

Deyak,Timothy A.,W. Charles Sawyer, and Richard L. Sprinkle, Changes in Income and Price Elasticities of US Import Demand, Economia Internazionale. pp.75-161, 1997.

Dixit, A.; Stiglitz, J. Monopolistic competition and optimum product diversity. American Economic Review, v. 67, n. 3, p. 297-308, 1977.

Erkel-Rousse, Hélène and Françoise Le Gallo, Price and Quality Competitiveness in International Trade: an Empirical Study on Twelve OECD Countries Cahier de la MSE Working Paper 2002-05; French version in:Economie et Prévision , 2002.

Erkel-Rousse, Hélène and Daniel Mirza, Import Price Elasticities: Reconsidering the Evidence, Canadian Journal of Economics, vol. 35, n. 2, p. 282-306, 2002.

Feenstra R.C. "New Product Varieties and the Measurement of International Prices", American Economic Review, Vol 84(1), pg 157-177, 1994.

Fontagné, L. and Frudenberg, M. Intra-Industry Trade: Methodological Issues Reconsidered. CEPII, Document de Travail, No. 97-01, 1997.

Frees, E.Longitudinal and Panel Data: Analysis and Applications for the Social Sciences. University of Wisconsin-Madison, 2003.

Gaulier, G. e Méjean, I. "Import prices, variety and the extensive margin of trade", Working Papers 2006-17, CEPII research center, 2006. 
Goldstein, Morris and Mohsin S. Khan, "Income and Price Effects in Foreign Trade," in Ronald W. Jones and Peter B. Kenen (eds.), Handbook of International Economics, Vol. 2, 1985.

Greenaway, D., Hine, R.C. and Milner, C.R. Country-Specific Factors and the Pattern of Horizontal and Vertical Intra-Industry Trade in the UK. Working Paper, 130, 77-100, 1994.

Greenhalgh C., P. Taylor and Wilson R. Innovation and export volumes and prices- A brokenupstudy ", Oxford Economic Papers, 46, pp.102-134, 1994.

Grossman G.M. "Import Competition from Developed and DevelopingCountries", Review of Economics and Statistics, Vol 64, pg 271-281, 1982.

Harberger, Arnold C., "A Structural Approach to the Problem of Import Demand," American Economic Review. Vol. 43, n. 2, pp.148-159, 1953.

Hausmann R., J. Hwang and D. Rodrik. 'What You Export Matters', Journal of Economic Growth, 12, $1-25,2007$.

Ioannidis E. \& P. Schreyer. Déterminantstechnologiques et non technologiques de l'accroissement des parts de marché à l'exportation ”, Revue Economique de l'OCDE, 29, 1,pp.187-226, 1997.

Kawamoto, S.; Santana, B; Fonseca, H.Elasticidade Renda e Elasticidade Preço das Exportações e das Importações de Produtos Industrializados no Brasil (2003-2010): Uma Avaliação Utilizando Dados em Painel.Revista de Economia, v. 39, n.2 (ano 37), p. 139-159, mai./ago. 2013.

Krugman, P. Scale Economies, Product Differentiation, and the Pattern of Trade. American Economic Review, Vol. 70, No. 5, p. 950-959, 1980.

Krugman P. R. "A Model of Innovation, Technology Transfer and the World Distribution of Income, Journal of Political Economy, Vol. 87, 1979, pg 253-266, 1979.

LEMOS, M. B. A Nova Geografia Econômica: uma leitura crítica. 2008. 170 f. Tese de Professor Titular, UFMG, Belo Horizonte, 2008.

Madsen, Jakob B., "On Errors in Variable Bias in Estimates of Export Price Elasticities," Economic Letters63, 1999).

Marquez J., McNeilly C. "Income and Price Elasticities for Exports of Developing Countries", Review of Economics and Statistics, pg 306-314, 1988.

Orcutt, Guy H., "Measurement of Price-Elasticities in International Trade," Review of Economics and Statistics. pp.117-32, 1950.

Rauch, J. E. (1999). Productivity gains from geographic concentration of human capital: Evidence from the cities. Journal of Urban Economics, 34(3):380-400, 2006.

Samuelson, P. A. The Transfer Problem and Transport Costs: Analysis of Effects of Trade Impediments. Economic Journal, vol. 64, n. 254, p. 264-289, 1954.

Santos, A. M. A, dos; Sousa, E. A., de; Jacinto. P. de A.; Tejada, C. A. O.“ Elasticidades Preço e Renda das Exportações e Importações: Uma Abordagem Através de dados em painel para os estados do Brasil”. Análise, Porto Alegre, Vol. 22, n. 2, pág. 202- 212, 2011.

Carmo, A.; Bittencourt, M. O comércio intra-industrial entre Brasil e os países da OCDE: decomposição e análise de seus determinantes. RevistaAnálise Econômica. Porto Alegre. v. 31, n. 60 , 2013.

Skiendziel, A. G.L. "Estimativas de Elasticidades de Oferta e Demanda de Exportações e de Importações Brasileiras." Brasília: Dissertação de Mestrado. Universidade de Brasília - Instituto de Ciências Humanas, 2008.

Spence, A. Product Selection, Fixed Costs, and Monopolistic Competition. Review of Economic Studies, vol. 43, issue 2, pages 217-35, 1976.

XU, B. Measuring China's export sophistication. Shanghai: China Europe International Business School, May 2007.

$\mathrm{Xu}, \mathrm{B}$.; Lu, J. Foreign direct investment, processing trade, and the sophistication of China's exports. China Economic Review, n. 20, p. 425-439, 2010.

Zagamé, P. Thanagopal,TRe-estimating International Elasticity of Substitution - A Preliminary Study of Quality Effect on Trade, 2005.

Zini JR, A. "Funções de exportação e de importação para o Brasil." Pesquisa e Planejamento Econômico 18 (3): 615-662, 1988. 
Ekanayake, E. M.; Halkides, M.; Rance, R.; Filyanova, I. Intra-industry trade between the United States and Latin America countries. The International Journal of Business and Finance Research, vol. 1, n. $2,2007$.

\section{ANEXO A- Metodologia das variáveis utilizadas}

\section{A1. Índice de Preços}

O índice de preços é calculado com base na formulação de Fisher na qual os preços de um bem em determinado período são comparados com os preços do mesmo bem em um período base. Sendo assim, o índice de preços do período 1 em relação ao período 0 é obtido por meio da seguinte expressão:

$$
I_{p}^{0,1}=\left\{\left[\left(\sum p_{i}^{1} \cdot x_{i}^{0}\right) /\left(\sum p_{i}^{0} \cdot x_{i}^{0}\right)\right]\left[\left(\sum p_{i}^{1} \cdot x_{i}^{1}\right) /\left(\sum p_{i}^{0} \cdot x_{i}^{1}\right)\right]\right\}^{1 / 2}
$$

Onde pé o preço médio do bem i em cada período e xé o peso (em toneladas) do bem i importado em cada período $(0,1)$. As comparações bilaterais anuais são transformadas em séries anuais pela forma encadeada, na qual a variação entre $t-1$ e $t+l$ é determinada pelo produto das variações entre $t-l$ e $t$ e entre $t$ e $t+1$; o encadeamento resulta em índices transitivos, aumenta a cobertura dos índices e reduz o viés das comparações sequenciais.

\section{A2. Especialização Setorial}

A especialização setorial é dada por:

$$
s p e_{k i j I^{\prime}}=\left(X_{k i} / X_{i}\right) /\left(\overline{X_{k I^{\prime}}^{j} / X_{i^{\prime}}^{j}}\right)
$$

Onde:

$$
\left(\overline{X_{k I^{\prime}}^{j} / X_{i^{\prime}}^{j}}\right)=\prod_{i^{\prime} \in I^{\prime}}\left(X_{k i^{\prime}} / X_{i^{\prime}}\right)^{a_{K i^{\prime} j}}
$$

$X_{k I}^{j}$, refere-se as exportações do bem $k$ pelo país $j$ considerando um conjunto $I^{\prime}$ de parceiros.

$X_{i^{\prime}}{ }^{j}$ refere-se as exportações totais do país $j$ para o país $i^{\prime} \epsilon I^{\prime}$.

Para realizar os cálculos, foi utilizado o PIB de cada parceiro comercial do Brasil, coletado no banco de dados do World Bank, a preços de 2005.

\section{A3. Índice de Comércio Intra-insdústria Horizontal e Vertical}

A construção dessa variável baseia-se no critério de similaridade do produto, de acordo com Greenaway, Hine e Milner (1994) e Fontagné e Freudenberg (1997). Esse critério define o padrão de diferenciação dos produtos a partir da razão $(\lambda)$ obtida da divisão do valor unitário do produto $(\mathrm{k})$ exportado (VUX $k i j t)$ e importado (VUM $k i j t)$ entre os países $i$ e $j$, no ano $t$, ou seja: $\lambda=\mathrm{VUX}_{k i j t} / \mathrm{VUM}_{k i j}$. Se a razão entre os valores unitários $(\lambda)$ se mantém próxima da unidade, considera-se que os produtos comercializados não possuem diferenças significativas, logo, os mesmos serão definidos como horizontalmente diferenciados, temos então um comércio intra-indústriahorizontal (CIIH). Caso contrário, quando a razão entre os valores unitários afasta-se da unidade, considera-se que os produtos comercializados são verticalmente diferenciados, nessa situação o comércio intra-indústria será vertical (CIIV).

O critério utilizado para definir se $\lambda$ está próximo ou afastado da unidade será baseado no intervalo de dispersão, definido por: $[(1-\alpha) ;(1+\alpha)]$. Assim, quando $\lambda$ pertencer a esse intervalo, consideramos que os produtos comercializados são horizontalmente diferenciados, caso contrário, os mesmos serão definidos como verticalmente diferenciados. Nos casos em que os produtos forem verticalmente diferenciados, podemos definir o CII, sob o ponto de vista do país exportador, como vertical inferior $\left(\mathrm{CIIV}_{\text {inf }}\right)$ ou como vertical superior $\left(\mathrm{CIIV}_{\text {sup }}\right)$, quando $\lambda<(1-\alpha)$ ou $\lambda>(1+\alpha)$, respectivamente. No primeiro caso, os produtos do país exportador possuem qualidade superior a dos produtos importados, e o contrário ocorre na segunda situação. 
Sendo assim, a variável utilizada no modelo foi a razão $\lambda$, quando os termos de troca não são muito diferentes e caem dentro de um dado intervalo (por exemplo entre 0,85 e 1,15) dizemos que os produtos têm a mesma qualidade, ou seja, são diferenciados horizontalmente. Se os termos de troca caírem fora do intervalo dizemos que a qualidade dos produtos é diferente, ou seja, os produtos são diferenciados verticalmente.Subjacente a esta metodologia está a hipótese de que os preços unitários das exportações em relação aos preços unitários das importações (os termos de troca) refletem as diferenças de qualidade.

O comércio intra-industrial horizontal $(\mathrm{CIIH})$ é geralmente definido como a troca simultânea de produtos horizontalmente diferenciados, ou diferenciados por variedade, ao passo que o comércio intraindustrial vertical (CIIV) é definido como a troca simultânea de bens verticalmente diferenciados, ou diferenciados por qualidade. Em tese, o comércio intra-industrial horizontal $(\mathrm{CIIH})$ deve ocorrer principalmente entre parceiros comerciais com semelhantes níveis de renda, enquanto o comércio intraindustrial vertical (CIIV) deve ocorrer entre países com distintos níveis de renda (Ekanayake, 2007). O comércio intra-industrial horizontal $(\mathrm{CIIH})$ é explicado a partir da nova teoria de comércio internacional (Krugman, 1979; 1980; 1981; Helpman e Krugman, 1985; Lancaster, 1980), que explicam esse padrão de comércio a partir de modelos teóricos que admitem competição monopolística, diferenciação horizontal de produtos e retornos crescentes de escala. Já o comércio intra-industrial vertical (CIIV) é explicado a partir das tradicionais teorias de comércio internacional, que explicam esse padrão de comércio a partir das vantagens comparativas dos países (Falvey, 1981; Falvey e Kierzkowski, 1987; Flam e Helpman, 1987). Dessa forma, as análises de custo de ajustamento e de bem-estar serão bastante distintas dependendo do tipo de comércio intra-industrial (Brülhart e Elliott, 2002).

\section{A.4 Indicador de sofisticação com ajuste para a qualidade}

A fim de construir um índice para medir a sofisticação da produção e examinar sua relação com o desenvolvimento tecnológico (Lall, et al., 2005; Rodrik, 2006; Hausmann, et al., 2007; Xu, 2010; Schott, 2008; Van Assche e Gangnes, 2007), os autores constroem um índice de produtividade a ser chamado dePRODY. Esse índice é definido pela média ponderada da renda per capita dos países exportadores de determinado produto, representando o nível de renda associado a cada um deles. Segundo Kume, et al. (2012), a ideia básica é de que os países, ao exportarem um bem, "revelam" o seu grau de produtividade de forma similar ao conceito de vantagem comparativa revelada. Como os salários nos países ricos são mais elevados, as exportações serão viáveis somente se forem compensadas por meio de uma melhor tecnologia. Essa maior produtividade pode ser decorrente não apenas de uma tecnologia mais avançada, mas também de outros fatores, tais como a dotação de fatores, a infraestrutura, as técnicas de comercialização e a fragmentação da produção. Assim, pode-se atribuir uma medida de produtividade, denominada grau de sofisticação,aos produtos exportados para qualquer classificação de mercadorias. Segundo Lallet al.(2005), a sofisticação se correlaciona muito bem com a tecnologia.

Cada país é indexado por $j$ e os produtos por $k$, sendoovalor total das exportações do país $j$ dado por:

$$
X_{j}=\sum_{k} x_{j k}
$$

Seja a renda per capita do país $j$ denotada por $Y_{j}$. Então o nível de produtividade associado ao produto $k$ é dado por:

$$
\operatorname{PRODY}_{k}=\sum_{j} \frac{\left(x_{j k} / X_{j}\right)}{\sum_{j}\left(x_{j k} / X_{j}\right)} Y_{j}
$$

em que:

$P R O D Y_{k}$ é a produtividade do produto $k$;

$x_{j k}$ é o valor das exportações do produto $k$ pelo país $\mathrm{j} ; \boldsymbol{X}_{j}$ é o valor das exportações totais do país $j$;

$Y_{j}$ é a renda per capita do país j; 
O numerador da fração, $x_{j k} / X_{j}$, é a participação do bem no total de produtos exportados pelo país $j$, o denominador, $\sum_{j}\left(x_{j k} / X_{j}\right)$, agrega as exportações de todos os países exportadores do bem $k$. Esse índice representa a média ponderada da renda per capita, em que a ponderação corresponde à vantagem comparativa revelada de cada país no bem $k$.

O ponderador da renda per capita é o indicador de vantagem comparativa revelada de Balassa (1965), normalizado para que a soma seja igual a um ${ }^{14}$.

O grau de sofisticação das exportações do país $j\left(E X P Y_{j t}\right)$, para cada anot, é dada por:

$$
E X P Y_{j t}=\sum_{k} \frac{X_{j k t}}{X_{j t}} P R O D Y_{k}
$$

A expressão (3) representa a produtividade de cada produtok ponderada por sua participação na pauta de exportação do paísj.

Xu (2010) afirma que a sofisticação não reflete perfeitamenteo nível de processamento tecnológico das exportações de um país, mas segundo o autor, a evidência mostra que os índices refletem o conteúdo tecnológico das exportações em certo grau. O autor apresenta em seu trabalho as correlações entre o índice de sofisticação das exportações e os gastos com $P \& D$ dos paísesda OECD. As correlações estimadas foram todas positivas, e apenas três indústrias de uso intensivo em recursos naturais apresentaram estimativas estatisticamente insignificantes. Também foram calculadas as correlações por país, os resultados indicam que o índice de sofisticaçãoé correlacionado positivamente com a relação entre $P \& D$ e PIB. Assim, o autor conclui que o indicador de sofisticaçãonão é uma medida perfeita,mas reflete em certo grau o conteúdo tecnológico das exportações.

Para medir a qualidade "dentro do produto", Xu (2010) constrói o seguinte índice de preço:

$$
q_{i J}=\frac{p_{i J}}{\sum_{j \in J}\left(\mu_{i j} p_{i j}\right)}
$$

Em que:

$p_{i j}$ é o preço do bem i exportado pelo país j.

O denominador é a média ponderada dos preços do bem $i$, exportado por todos os $J$ países, sendo $\mu_{i j}$ a participação das exportações do bem $i$ pelo país $j$ no total exportado do bem $i$, o que reflete a importância relativa do país $j$ nas exportações desse bem.

Xu (2010) mostra que, para um mesmo produto, há correlação positiva entre preço de exportação de um país e sua renda per capita, esses resultados confirmam a hipótese de que países ricos exportam produtos de maior qualidade e os países pobres em geral exportam bens de qualidade inferior. Dada a importância da qualidade, o autor incorpora os preços dos produtos (como proxy para qualidade) nas medidas de sofisticação. Para isso,acrescenta um multiplicador de qualidade que ajusta o índice de produtividade(PRODY), definido pela seguinte expressão:

$$
Q P R O D Y_{i j}=\left(q_{i j}\right)^{\theta} \times P R O D Y_{i}
$$

Em que:

$\left(q_{i j}\right)^{\theta}$ representa o multiplicador de qualidade;

\footnotetext{
${ }^{14} \mathrm{O}$ índice de vantagem comparativa revelada tradicional de Balassa (1965) mede, no denominador, a participação das exportações mundiais de um determinado produto no total das exportações do mundo. Assim, se a participação das exportações desse bem no total das exportações do país (numerador) for superior à parcela das exportações mundiais do mesmo produto no total exportado pelo mundo, o índice será maior que 1 . Caso contrário, o índice será menor que 1 . Se o país j não exporta o bem $k$, o índice de vantagem comparativa será nulo. O ajuste feito no índice permite que a soma dos índices de vantagem comparativa de todos os países seja igual a 1.
} 
$\theta$ é o parâmetro que mede o grau de ajuste de qualidade, onde $\theta=0$ representa nenhum ajuste para a qualidade.

Com esses resultados obtemos um indicador de produtividade ajustada pelos preços para cada produto, este será usado como proxy para a qualidade dos bens importados. 